\title{
Validation of the University of Manchester Drug Misuse Database
}

Tim Crabbe, Michael Donmall, Tim Millar

\begin{abstract}
Objective-The study was conducted to assess the validity and quality of data held by one of the UK regional drug misuse databases (DMD).

Design-The research was multi-centred and used retrospective analysis to assess the validity of data held on the database.

Setting-The Regional Database is managed at the University of Manchester Drug Misuse Research Unit and uses data returned by medical and non-medical services within the UK's former North Western Regional Health Authority.

Material-The research was largely based on analysis of the reporting or nonreporting to DMD of 1526 presentations by drug users to four community drug teams (CDTs) during the course of 1993. Two datasets were used: the DMD dataset, based on returns to the regional database from the agencies in question; and agency client records. Additionally the data included on a random sample of 300 database forms returned by these CDTs were compared with information contained in client records.
\end{abstract}

Main outcome measures-the study reports on how well DMD is functioning in relation to the correct reporting of episodes of problem drug use and the quality of data held.

Results-A very high level of agreement $(0.875 \pm 0.017,95 \%$ CI, $\kappa$ coefficient 0.728$)$ was established between reports sent in to the database and those expected by examination of agency records. The database figures underestimated the total number of episodes that should have been reported by a factor of $\mathbf{0 . 0 0 8}$. It was also established that $0.906( \pm 0.018,95 \% \mathrm{CI})$ of the reports made to the database were made correctly, that $0.178( \pm 0.030,95 \% \mathrm{CI})$ of eligible presentations were not reported, and that $0.166( \pm 0.030,95 \% \mathrm{CI})$ of ineligible presentations were mistakenly reported. Lastly, it was established that data were unnecessarily missing or inaccurately recorded in 0.027 of cases and that data entry errors occurred in 0.015 of cases.

Conclusions-The validation project showed that the DMD system is very reliable, providing accurate measures of the extent and nature of presenting problem drug use in the region under study. (F Epidemiol Community Health 1999;53:159-164)

The University of Manchester Drug Misuse Database (DMD) was developed in 1986 by a
Research Team working on a DHSS study evaluating the impact of community drug initiatives. ${ }^{1-3}$ The database originally encompassed reports about the social background and drug use profiles of all drug users presenting to medical and non-medical services in three District Health Authorities within the UK's North Western Regional Health Authority. In 1987 the system attracted Regional Health Authority (RHA) funding and was introduced in all medical and relevant nonmedical agencies throughout the Region.

In 1989 the University of Manchester Drug Research Unit was commissioned by the Department of Health and Social Security to adapt DMD for use in other regions. After recommendations from the UK's Advisory Council on the Misuse of Drugs ${ }^{45}$ and others, in relation to improvements in drug reporting systems, the Department of Health issued $\mathrm{HC}(89)$ 30, asking RHAs to set up a drug misuse database to "monitor trends in drug misuse and the use of drug misuse services and introduce a system for providing this information to the Department". This request was accompanied by a requirement on the Regions to return a completed KO71 form to the Department of Health from all of their Districts every six months, summarising the data processed by the new databases. The Department also recommended at this time that the software developed for the North Western Region be adopted for this purpose.

Of the 16 former UK health areas (excluding Northern Ireland), at the time of the study, 12 used the adapted $\mathrm{DMD}^{6}$ and three others used systems based on DMD but which either include additional data items and/or use different software. Totally separate definitions, methods of data collection, and software were used in only one region.

DMD is a paper based system that is driven by the completion of DMD forms by agency workers and doctors to whom clients have presented with a drug problem. Staff at those agencies and surgeries that contribute to the database should complete a form at first contact for "every client who presents to (their) service with a recent drug problem of any kind". Further forms should be completed for the same clients when they re-present with a drug problem after an absence from contact of six months or more.

The forms themselves include self carboning copies, one of which is sent to the regional database centre for processing using a specially designed software package. The top copy is kept for filing in the agencies' own client notes. A wide range of data is recorded on the forms, 
which can be divided into a number of sets, each with a different role and degree of importance. The first set is essential, and includes certain items that are necessary to prevent double counting when a client presents to more than one agency. This is the so called "attributor" and includes first and last initials, date of birth, and sex. The second set of data provides the core information and relates to trends in drug misuse, client behaviour, and details of the agencies and personnel dealing with the client. Another set of data helps to establish the social and treatment profile of presenting drug users and the final set remains confidential to the agency itself and is recorded on the front sheet of the form only.

The DMD system has achieved good coverage across the UK with an estimated $100 \%$ compliance from the specialist drug treatment agencies in the North Western area and between $85-95 \%$ elsewhere. From the start, the DMD has sparked a moderately contentious debate about the role that it serves and the anonymity that it offers to clients whose drug use and social profiles are reported to the database..$^{7-9}$ Recently, with the demise of the Home Office Addicts Index (May 1997), there has been increased interest in modifying the DMD to take on a re-reporting element so as to meet the need for prevalence information. With the exception of this study and one undertaken in North Thames, ${ }^{10}$ there has been little focus on the question of whether the system is capable of delivering the information that it was designed to gather. Certainly, all of the regional databases produce at least annual agency and district reports with statistics about presenting drug misuse, but the question as to whether these reports provide an accurate representation of the drug problems presented to agencies in the UK (and particularly England) has remained largely unanswered.

This question has been considered by a major assessment of the validity and quality of data held by one of the regional databases and the understanding that agency staff have of how the system works. ${ }^{11}$ The study, which was conducted in the region covered by the former North Western Regional Health Authority, was part of a wider project concerned with the preparation of a UK national focal point for the European Monitoring Centre for Drugs and Drug Addiction. ${ }^{12}$ It was primarily interested in whether existing drug misuse reporting systems provide an accurate picture of the number and type of drug users presenting to drug services. Consideration was also given to the quality and completeness of data returned to the regional database and the accuracy with which that information was entered onto the system. Other aspects, such as the attitude of agency staff towards the database, were also investigated $^{13}$ but are not reported on here.

\section{Methods}

AGENCY SELECTION

Almost $70 \%$ of database forms that are returned to the regional database are sent in from Community Drug Teams $(\mathrm{CDTs})^{14}$ so it was decided to concentrate the validation exer- cise on these agencies. The central consideration in the selection process then became the scale of returns made by CDTs to the regional database, as the validation process was primarily concerned with the validity of returns that are made to the database.

The need to consider other factors, such as the identification of "false" negative returns (those returns that were not made when they should have been), necessitated the inclusion of an agency making rather less returns than the others, to identify whether this is happening because there are fewer presenting drug users or because there is any misunderstanding of the reporting system. The review of an agency making fewer returns also dealt with the possibility that by concentrating on the agencies making large numbers of returns we selected those agencies that are known to be operating the DMD efficiently and without obvious problems, which might have undermined the validation process.

A third factor to consider in the selection process was the location of agencies. It is clear that there is an increasing range of possible treatment centres for drug users the closer their proximity to the city of Manchester (a large conurbation within the health region being considered), ranging from CDTs, nonstatutory drugs agencies and a number of GPs with an understanding of drug problems and a willingness to treat drug users. By contrast, drug users in more outlying parts of the region have access to a narrower range of services and are more often forced to rely on the local CDT and one or two accommodating GPs. In turn this means that drug users in central Manchester are likely to present to a number of services over a given period of time and are consequently likely to have more episodes recorded on the database than drug users presenting to services in more outlying areas. This raises the chance of discrepancies arising in the data provided about these clients by different services reporting to the DMD.

CDTs were chosen in areas where clients have a range of access to alternative drugs services, using central Manchester as the "epicentre of choice" with a declining range of choice the more detached the area is from the City. Three appropriate bands were identified: the City of Manchester; Greater Manchester; the County of Lancashire.

However, the most important element remained the scale of returns to the database and so the number of CDTs selected had to reflect the number of reported users in each of these bands and the final choice of CDTs had to relate to the number of returns from each district. In 1992 the number of presenting users reported in the City of Manchester was 1218 (27.7\% of regional total), in Greater Manchester (excluding the City) the figure was 1743 $(39.6 \%)$ and in Lancashire it was 1431 $(32.5 \%)$. On this basis we selected one CDT from the City, two from Greater Manchester, and one from Lancashire. One CDT was selected from the City of Manchester and one from Lancashire that had made the highest numbers of returns but that also corresponded 
to the overall proportion of returns from these regional bands. The CDTs making the largest and smallest number of returns to the database were selected from Greater Manchester. In this way we were also able to establish whether there were any specific reporting errors contributing to the low and high levels of returns from these particular CDTs as well as maintaining the proportion of returns to be studied from each regional band because of the greater overall consistency of reporting from Greater Manchester CDTs.

THE VALIDATION PROCESS

The research was primarily concerned with validating the extent of reporting errors to $\mathrm{DMD}$, the quality of the data made available, and the reasons for any errors or gaps in the information provided. It was developed in a series of stages.

Once the selected agencies had seen the research proposal they all gave their approval to the study, agreed to participate and welcomed the opportunity that it would offer to establish the full extent of their current presenting client caseloads. The research initially focused on the identification of "false" positive and negative returns to the database, that is, those returns that were made when they should not have been (false positives) and those returns that were not made when they should have been (false negatives). This exercise was based on fieldwork research at the four CDTs and entailed the use of two datasets: the DMD dataset for the agencies selected (based on returns to the regional database from the agencies in question); and agency client records, which usually include the front copy of the relevant database forms.

A trawl was made through agency client records to establish attributable data for all clients in contact with the CDTs during 1993. A check was then run to identify whether a return had ever been made to the DMD by the CDTs for each of these clients and a further check was run to see whether any returns to DMD had been made during the 12 months of 1993. Reference was then made back to "contact records" in the agencies' client notes to establish the extent of false positive and negative reporting during 1993 - that is, those returns that were made when they should not have been and those returns that were not made when they should have been.

The quality of the information reported to the database was then assessed by checking the information recorded on a random sample of "hard" copy database forms returned to the database during 1993, against information held on those clients by the agencies at the time that the forms were completed. Information was gathered on those data items that were omitted from, or inaccurately recorded on, the relevant DMD forms.

Before considering the extent of missing data it was necessary to make a number of distinctions between different types of reporting error. Firstly, there are items of data that have been omitted from forms returned to the database; secondly, there are items of data that have been completed inaccurately on database forms and; thirdly, there are items of data that have been omitted from database forms but where the information can be inferred from other categories of data that have been completed.

It is also important to note that not all of the data items included on the DMD forms have the same significance. Some are more "important" than others. It was necessary to allow for these factors in the analysis, and so a "status" was allocated to each of the data items on the $\mathrm{DMD}$ form on a scale of 1 to 5 , where 1 is essential and 5 is desirable. The particular status for each item was allocated according to two factors. The ability of the system to include returns where the item in question was missing and the "value" of the data item in terms of data utilisation.

Certain items, such as those that make up the attributor, are essential and have a status of 1 , as without them a database return cannot be entered onto the system. Other items, including many of those with a status of 5 , are very important but relate to "action planned" rather than action taken and so are of more use to the agency making the return than regional planners. Similarly, the different status given to the "main" drug (status 1) and "other" drugs (status 2) recorded on the forms does not imply that one element of drug use is more important than any other, just that it is more important for the purpose of data processing and the validation exercise, as no return would be entered without the indication of a main drug of use.

The validation of data processing centred on a review of a sample of "hard copy" database returns, which were checked against the information held on the corresponding records on $\mathrm{DMD}$ to identify inconsistencies. Checks were run by reverse verification on omitted data and selected coded data items on DMD and cross checked against the relevant hard copies of database returns. As with the data quality test a record was kept of those items of data that were found to be missing or inaccurately recorded.

\section{STATISTICAL METHODS}

A rule (when to return a database form) was established that governs whether an event (the return of a database form) should or should not happen. The results are best considered as a measure of inter-rater reliability, that is, whether the agency made a return to the database, and whether the study concluded that a return should have been made.

From these data it was possible to calculate the proportion of true positives (returns made when they should have been), true negatives (returns not made when they should not have been), false positives (returns made when they should not have been) and false negatives (returns not made when they should have been). Measures of agreement were calculated and confidence levels applied, along with the $\kappa$ coefficient, a measure of reliability that gives a coefficient of agreement for nominal scales, in which the proportion of agreement has been corrected for chance. ${ }^{15}$ The number of false positive and false negative returns to the 
Table 1 Conformity of reporting of episodes of problem drug use to DMD with the rules that govern the system

\begin{tabular}{|c|c|c|c|c|c|c|}
\hline & & \multicolumn{2}{|c|}{ Reported } & \multicolumn{2}{|c|}{ Not reported } & \multirow[b]{2}{*}{ Total } \\
\hline & & & $95 \% C I$ & & $95 \% C I$ & \\
\hline \multirow[t]{2}{*}{ Should be reported } & $\mathrm{n}$ & 880 & & 99 & & 979 \\
\hline & $\begin{array}{l}\text { row } \mathrm{p}_{\mathrm{o}} \\
\text { col p }\end{array}$ & $\begin{array}{l}0.899 \\
0.906\end{array}$ & $\begin{array}{l} \pm 0.019 \\
\pm 0.018\end{array}$ & $\begin{array}{l}0.101 \\
0.178\end{array}$ & $\begin{array}{l} \pm 0.019 \\
\pm 0.032\end{array}$ & \\
\hline \multirow[t]{3}{*}{ Should not be reported } & & 91 & & 456 & & 547 \\
\hline & row $\mathrm{p}_{\mathrm{o}}$ & 0.166 & \pm 0.031 & 0.833 & \pm 0.031 & \\
\hline & $\operatorname{col} \mathrm{p}_{\mathrm{o}}$ & 0.094 & \pm 0.018 & 0.834 & \pm 0.032 & \\
\hline Total & $\mathrm{n}$ & 971 & & 555 & & 1526 \\
\hline
\end{tabular}

Table 2 Breakdown of reporting errors in terms of false positives and false negatives for the three client groups identified

\begin{tabular}{|c|c|c|c|c|c|c|c|}
\hline \multirow[b]{2}{*}{ Client group } & \multicolumn{3}{|c|}{ False negatives } & \multicolumn{3}{|c|}{ False positives } & \multirow[b]{2}{*}{ Total } \\
\hline & $n$ & row $p_{o}$ & $95 \% C I$ & $n$ & row $p_{o}$ & $95 \% C I$ & \\
\hline Ongoing & 3 & 0.040 & \pm 0.040 & 72 & 0.960 & \pm 0.040 & 75 \\
\hline Re-presenting & 59 & 0.868 & \pm 0.081 & 9 & 0.132 & \pm 0.081 & 68 \\
\hline New & 37 & 0.787 & \pm 0.117 & 10 & 0.213 & \pm 0.117 & 47 \\
\hline Total & 99 & & & 91 & & & 190 \\
\hline
\end{tabular}

database were then established for the three different types of client identified by the research.

\section{Results}

REPORTING OF EPISODES OF PRESENTING

PROBLEM DRUG USE

Table 1 illustrates the number of times that database returns were correctly and incorrectly made and not made in relation to the reporting of episodes of presenting problem drug use.

In total, 1526 events (potential reports to the database) were considered. If the rule (when to report) had been applied correctly, 979 of these should have resulted in a report and 547 should not. In reality, 971 reports were made and 555 were not. Hence the database figures underestimated the total number of episodes that should have been reported by a factor of 0.008 .

Of the 979 events that should have been reported, $880(0.899,0.01995 \%$ CI) were correctly reported and 99 (0.101, 0.019 95\% CI) were not. Of the 547 events that should not have been reported, $91(0.166,0.03195 \%$ CI $)$ were mistakenly reported and $456(0.833$, $0.03195 \%$ CI) were not. Hence, allowing for $95 \%$ confidence intervals, it was more likely for an ineligible event to be reported than it was for an eligible event not to be reported-that is, the sensitivity of the reporting rule outweighed its specificity, albeit by a small degree.

Conversely, of the 971 events that were reported to the database, $880(0.906,0.018$ $95 \%$ CI) should have been and 91 (0.094, $0.01895 \% \mathrm{CI}$ ) should not. Of the 555 events that were not reported, $99(0.178,0.03295 \%$ CI) should have been and $456(0.834,0.032$ $95 \%$ CI) should not. Hence, allowing for $95 \%$ confidence limits, the proportion of eligible events excluded from the database figures was greater than the proportion of ineligible events included - that is, overall, the database figures resulted in a small underestimate of the number of eligible events.

For $1336(0.875,0.01795 \% \mathrm{CI})$ of the total number of events considered the rule was applied correctly. Allowing for agreement because of chance, the overall agreement between the rule (when to report) and the event (whether a report was made) was 0.728 (Cohen's $\kappa$ ).

For 190 events $(0.125,0.01795 \% \mathrm{CI})$ the rule was incorrectly applied. Of these, 99 (0.521, $0.07195 \% \mathrm{CI})$ related to false negatives and $91(0.479,0.07195 \% \mathrm{CI})$ to false positives.

Looking at the findings in more detail (see table 2) it was possible to identify patterns in the types of error that were made for different "types" of client. We identified three client groups, the "ongoing client", who was in contact with one of the four CDTs on the 1 January 1993, the "re-presenting client", who had been in contact with one of the CDTs before 1993 and re-presented during 1993, and the "new client" who presented to one of the CDTs for the first time during 1993.

For each of these client types there was a different pattern of false reporting. For ongoing clients some $96 \%$ of relevant reporting errors made were concentrated in the false positive category. For new clients $79 \%$ of relevant errors related to the non-reporting of initial presentations (false negatives). For representing clients $87 \%$ of the relevant reporting errors made related to the failure to report new episodes (false negatives).

THE QUALITY OF DATA REPORTED

Table 3 records the extent of missing and inaccurate information for each "status" of data category on a random sample of 300 database forms returned to DMD during 1993. This sample provides us with an accurate picture of the situation in the full database, with a sampling error of between $2 \%$ and $3 \%$ at $95 \%$ confidence.

When considering these findings the reader should bear in mind the fact that in 101 of the 196 cases of inaccurate data associated with "Status 3" categories, the missing information could be inferred from other data items on the database forms that had been completed. For example, the space for workers to record whether the client has "ever injected" is often left blank where the space for "injected in past month" is completed with a positive response.

\section{DATA PROCESSING}

Using the same "Status" definitions for inaccurate reporting as were used for data quality, the overall rate of data entry error was found to be $1.5 \%$, this rate fell to $0.6 \%$ for "Status 1 " data categories and rose above $5 \%$ for only four of the 52 individual data items on the forms.

Table 3 Reporting "errors" ( $n(\%))$ by status of data category on a sample of 300 database forms returned to DMD during 1993

\begin{tabular}{lll}
\hline $\begin{array}{l}\text { Status of data } \\
\text { category }\end{array}$ & $\begin{array}{l}\text { Data missing } \\
\text { (300 forms) }\end{array}$ & $\begin{array}{l}\text { Incorrect data or } \\
\text { "available" data } \\
\text { missing (300 forms) }\end{array}$ \\
\hline Status 1-6 items & $11(0.6)$ & $11(0.6)$ \\
Status 2-15 items & $226(5.0)$ & $126(2.8)$ \\
Status 3-8 items & $223(9.3)$ & $196(8.1)$ \\
Status 4-12 items & $517(14.4)$ & $146(4.1)$ \\
Status 5-11 items & $216(6.5)$ & $100(3.0)$ \\
\hline
\end{tabular}




\section{Discussion}

The results of this research show that the DMD system works very reliably in the region covered by the former North Western Regional Health Authority.

The number of cases of inaccurate reporting to the database were minimal overall $( \pm 6.5 \%)$ and the patterns of reporting errors that were identified were themselves in line with what might have been expected, with the overall direction of error being very slightly towards under-reporting. False positive reporting, particularly among ongoing clients, seems to reflect a general, although limited, misunderstanding of the definition of a new episode. The correct definition of a new episode is when a client presents to an agency with a drug problem for the first time or after an absence from contact with that agency of six months or more. A DMD form should only be returned to the database in these circumstances. The vast majority of the false new episodes were identified in the ongoing client category and were in relation to clients for whom a previous database form had been completed more than six months ago but who were last seen by the team less than six months ago.

This potential area of confusion was apparent to the system designers before the commencement of the research, and the situation has probably improved recently with the addition to the database forms of the direct question "Has the client visited this agency in the past 6 months?", which will act as a screen to this type of reporting error in future.

The tendency towards non-reporting of new episodes among re-presenting clients would seem to contradict the pattern of reporting associated with ongoing clients. This can best be explained by the identification of a number of grey areas in relation to this group, where clients seem to have dropped out of contact with the agency for a period of more than six months and yet a return was not made for a new episode upon resumption of contact with the agency. In some cases it became clear that contact had been maintained, but on an informal basis, which did not necessitate the addition of information to the clients' notes but which did override the need to report a new episode. These cases were not recorded as false negatives but in other cases, while a similar situation may have existed, there was insufficient information to establish whether contact had been maintained and so a false negative was recorded. This may have led to an overstatement of this type of reporting error.

The main reporting error among new clients was the failure to report the presentation at all. There are always likely to be problems of this nature in relation to new clients because of the uncertain and hesitant nature of many clients who present to a drug service for the first time. Contact notes are sometimes opened for clients making informal contact with the agency before a full assessment for which an appointment is made at a future date. In many cases these clients do not then keep their appointment for the full assessment and consequently
KEY POINTS

- DMDs are the main source of treatment information about problem drug users in the UK; it is important that the data are accurate and reliable.

- A major validation study has been carried out on the DMD in North West England.

- The study concludes that the DMD system is very reliable, and capable of delivering accurate estimates of the extent and nature of presenting problem drug use.

- Measures should be put in place to ensure that all DMDs provide accurate and reliable data.

no database form is returned despite the client notes giving the impression that contact had been made with a presenting problem drug user.

Turning to the question of data quality it is immediately clear from table 3 that there are some items of data that are regularly omitted from DMD forms returned to the database. However, this is often because of the nonavailability of the information rather than a reporting error, as was particularly the case in relation to the "postal district" category. Other items are omitted on the basis outlined earlier, where the answer can be inferred from a previous response.

Importantly, the worst reporting errors seem to have been concentrated among the less significant data categories. Among those data items with a status of 1 the information was not reported in only 11 cases on the 300 forms reviewed, across a total of six data items $(0.6 \%)$ and was found to be inaccurate or omitted when the data were available in the same number of cases. It should be noted though that the information on a DMD form cannot be entered onto the database if any one of four of these data items is missing. Those data items given a status of 2 include several questions that relate to patterns of injecting and sharing. Missing data in this area may then reflect a hesitancy on the part of agency staff to probe too deeply and clients to freely report their injecting behaviour at onset rather than reporting "errors".

In summary the validation project has shown that the DMD system is a very reliable one, providing accurate measures of the extent and nature of presenting problem drug use in the region covered by the former North Western Regional Health Authority. The fact that the DMD system was developed in this region and has operated there for longer than it has in other parts of the country may raise doubts about the validity of data held on databases elsewhere, ${ }^{10}$ which will need to be investigated further, but this study has demonstrated that the system is capable of delivering the information it was designed to gather. Measures should be established to ensure that data from all DMDs are accurate and reliable. 
This article is based on research that has been supported by the National Addiction Centre and conducted in relation to the European Community's REITOX Project - EMCDDA preparatory work. Thanks are due to John Strang for his assistance in establishing the project, to the agencies that participated in the research, to Joanne Jones at the Drug Misuse Research Unit, and to Julie Morris of the Medical Statistics Support Unit, University of Manchester, for statistical advice.

1 Strang J, Donmall MC. Drug addiction - A new notification form. Manchester Medicine 1985: September.

2 Donmall MC, Webster A, Strang J, et al. The introduction of community based services for drug misusers: impact and outcomes in the North West 1982-86. Report for the DHSS Homelessness and Addiction Research Liaison Group. Manchester: University of Manchester, 1989.

3 Donmall MC. Towards a National Database. Druglink. London: Institute for the Study of Drug Dependence, 1990;5:10-12.

4 ACMD. AIDS and drug misuse. Part 1. London: HMSO, 1988

5 ACMD. AIDS and drug misuse. Part 2. London: HMSO,

6 Donmall MC. The drug misuse database. London: Department of Health, 1990.
7 Davies $\mathrm{P}$, Jones $\mathrm{M}$, Ghodse $\mathrm{H}$. In confidence. Druglink. London: Institute for the Study of Drug Dependence, London: Institute for the

8 Mott J, Caddle D, Donmall MC. "Letters". Druglink. London: Institute for the Study of Drug Dependence, January/February 1994.

9 Jones M. "Letters". Health Service fournal 1994; June.

10 Hickman M, Sutcliffe H, Sondhi A, et al. Validation of regional drug misuse database: implications for policy and surveillance of problem drug use in the UK. BMF 1997;315:581

11 Crabbe T, Donmall MC. REITOX Project- EMCDDA preparatory work epidemiological and statistical function: The Drug Misuse Database Validation Study. Manchester: University of Manchester Drug Misuse Research Unit, 1994.

12 Council Regulation (EEC) No 302/93-8 February 1993 on the establishment of a European monitoring centre for drugs and drug addiction.

13 Crabbe T. Drug workers and the drug misuse database. International fournal of Drug Policy 1995;6:31-8.

14 Millar TW, Donmall MC. Drugs in the North West: The extent and nature of presenting problems in North Western RHA 1992. Manchester: University of Manchester Drug Research Unit, 1993.

15 Cohen J. Co-efficient of agreement for nominal scales. Educational and Psychological Measurement 1960;20:37-46. 